\title{
Saint-Bertrand-de-Comminges, Valcabrère
}

\section{(2) OpenEdition \\ Journals}

Édition électronique

URL : http://journals.openedition.org/adlfi/10499

ISSN : 2114-0502

Éditeur

Ministère de la culture

Référence électronique

"Saint-Bertrand-de-Comminges, Valcabrère », ADLFI. Archéologie de la France - Informations [En ligne], Midi-Pyrénées, mis en ligne le 01 mars 1997, consulté le 19 avril 2019. URL : http://

journals.openedition.org/adlfi/10499

Ce document a été généré automatiquement le 19 avril 2019

(C) Ministère de la Culture et de la Communication, CNRS 


\section{Saint-Bertrand-de-Comminges, Valcabrère}

Date de l'opération : 1989 - 1991 (PA)

Inventeur(s) : Petit Catherine

1 Au-delà des fouilles programmées entreprises, depuis 1985, sur le site de la ville antique de Lugdunum (Gallia Informations, 1989: 99-104), qui avaient pour but de vérifier mais surtout de rétablir des bases de données fiables, il est apparu nécessaire d'effectuer un relevé systématique des structures apparaissant à l'aide de prospections aériennes, afin de définir les limites de la cité antique.

2 En effet, les recherches anciennes concernaient plutôt les monuments publics que l'habitat privé, la voirie, les axes de pénétration et les nécropoles. La mise en place d'une opération de prospection aérienne limitée à la cité, a, dès 1986 (Gallia Informations, 1989 :172, fig. 98), révélé une urbanisation étendue sur plusieurs dizaines d'hectares, jusqu'alors inconnue pour sa plus grande part.

3 Il convient donc de signaler le repérage du tracé supposé de la voie de Dax (Aquae) à AygoBero, orientée vers le forum, et de celle de Toulouse (Tolosa), qui a été repérée à Valcabrère, le Couvent, avec une orientation est-ouest qui permet de la raccorder au cardo maximus. Un axe secondaire partant de leur point de jonction se dirige vers le nord en direction de l'amphithéâtre puis du port fluvial de la Garonne.

4 En ce qui concerne la trame urbaine, il s'avère nécessaire de réactualiser l'état des connaissances puisqu'elles vont bien au-delà des observations effectuées par Bernard Sapène en 1964. Trente ans après, de nouvelles structures apparaissent dans divers secteurs jusqu'alors méconnus: à l'ouest d'une part, à Las Contrades, Bernet, Herranne; et plus à l'ouest d'autre part, sur la commune de Valcabrère à Artex, SaintJust-de-Valcabrère, le Couvent (Fig. $\mathrm{n}^{\circ} 1$ : Le Couvent. Voiries et structures d'habitat), Las Campagnes, La Coune, etc. Cela apporte une vision renouvelée de l'extension de l'urbanisme.

5 Le système de voirie a également bénéficié de nouvelles informations, soit en précisant les découvertes antérieures, soit en révélant de nouveaux axes : cardines (orientés nord- 
nord-est-sud-sud-ouest mais aussi nord-nord-ouest-sud- sud-est) et decumani (nordnord-ouest-sud-sud-est). Leurs différences d'orientation sont une des caractéristiques de la trame urbaine de Lugdunum, qui ne comporte pas moins de sept directions différentes. Cela détermine l'implantation du centre monumental, des Thermes du Nord et du quartier de Signan, puis de la voie à l'est de la basilique chrétienne ou du camp de Tranquistan.

D'autres insulae complètent le plan défini par Bernard Sapène, au sud et à l'est des Thermes du Nord dans le secteur de Las Vignettes, ainsi que dans les Sales Arrouges au nord du macellum où les structures sont orientées sur le cardo maximus et où a pu être complété le plan déjà partiellement reconnu, en 1988, d'une domus à cour interne orientée au sud. À Coupéré, le grand édifice (corps principal allongé, avec deux ailes délimitant une cour intérieure), considéré comme isolé, est en réalité contigu à une seconde construction d'orientation différente.

7 De ces campagnes de prospections résulte une réinterprétation architecturale puisque le bâtiment rectangulaire à corps unique de Signan, sondé par Raymond Lizop puis par Bernard Sapène correspond en réalité à trois bâtiments parallèles juxtaposés, avec porche à l'est ; sans doute des édifices cultuels établis sur un podium commun.

8 Plus au nord, dans la plaine de Signan, un édifice rectangulaire à abside semi-circulaire, orienté sur un cardo est également interprété comme un lieu de culte, alors que la découverte la plus intéressante est celle d'un bâtiment enforme de " $U$ ", presque accolé aux Thermes du Nord (Fig. $n^{\circ} 2$ : Las Vignettes.Temple à triple cella au nord desThermes du Nord). Repéré partiellement par Catherine Petit, en 1989, puis dans sa totalité dans le courant de la même année par Georges Pradalié, il s'inscrit dans un rectangle $(34,70 \mathrm{~m} \times 26,30 \mathrm{~m})$ appuyé sur un cardo, à partir duquel se développe une large galerie en forme de « $\mathrm{U}$ » qui délimite une vaste cour, fermée à l'ouest par une triple cella. Cet édifice, sans doute un temple, repose sur un espace étroit ouvert sur les Thermes; mais tout cela méritera confirmation.

\section{ANNEXES}


Fig. $n^{\circ} 1$ : Le Couvent. Voiries et structures d'habitat

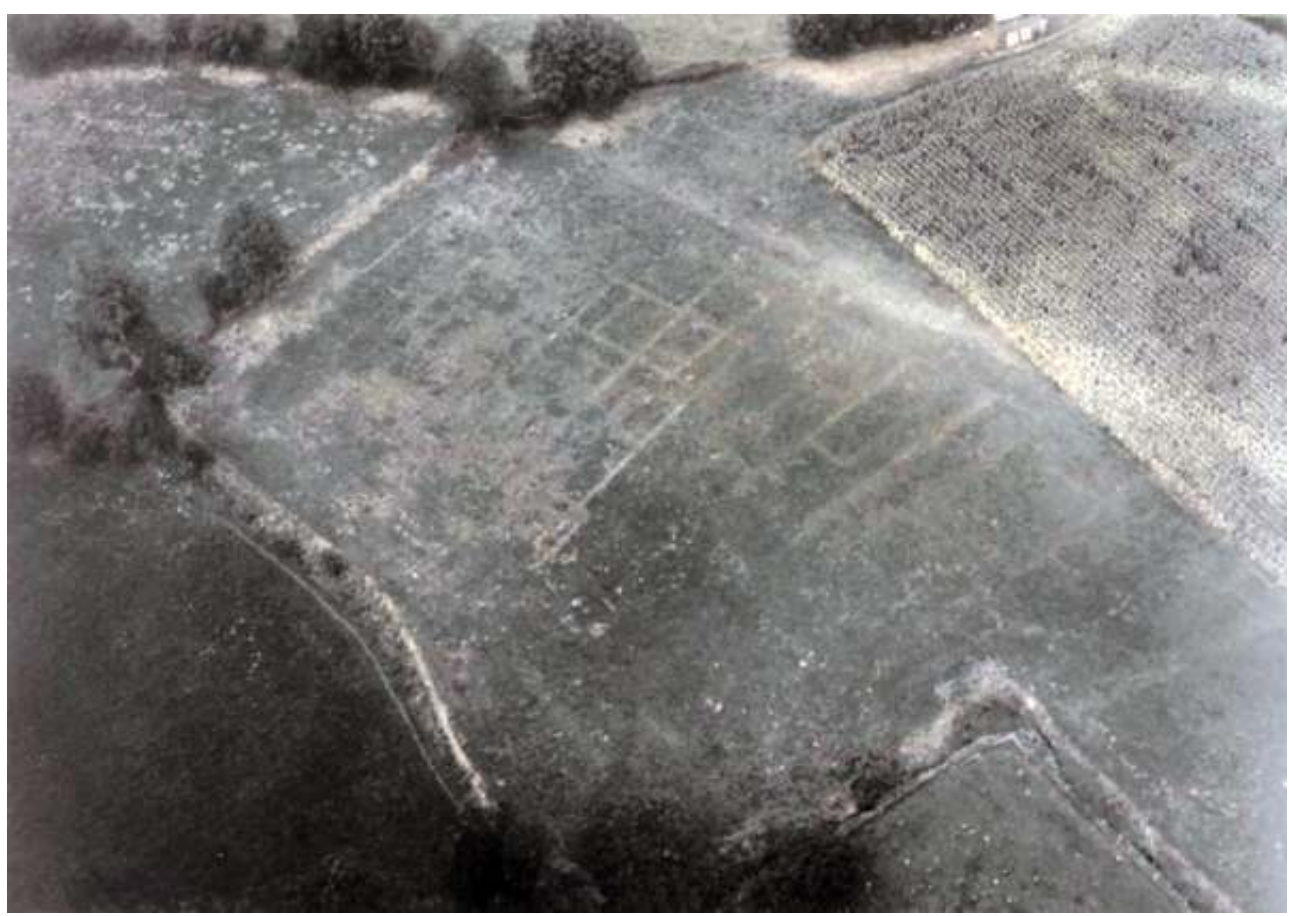

Auteur(s) : Petit, Catherine. Crédits : GI 1997 ; CNRS Éditions 1998 (1991)

Fig. $\mathrm{n}^{\circ} 2$ : Las Vignettes. Temple à triple cella au nord desThermes du Nord

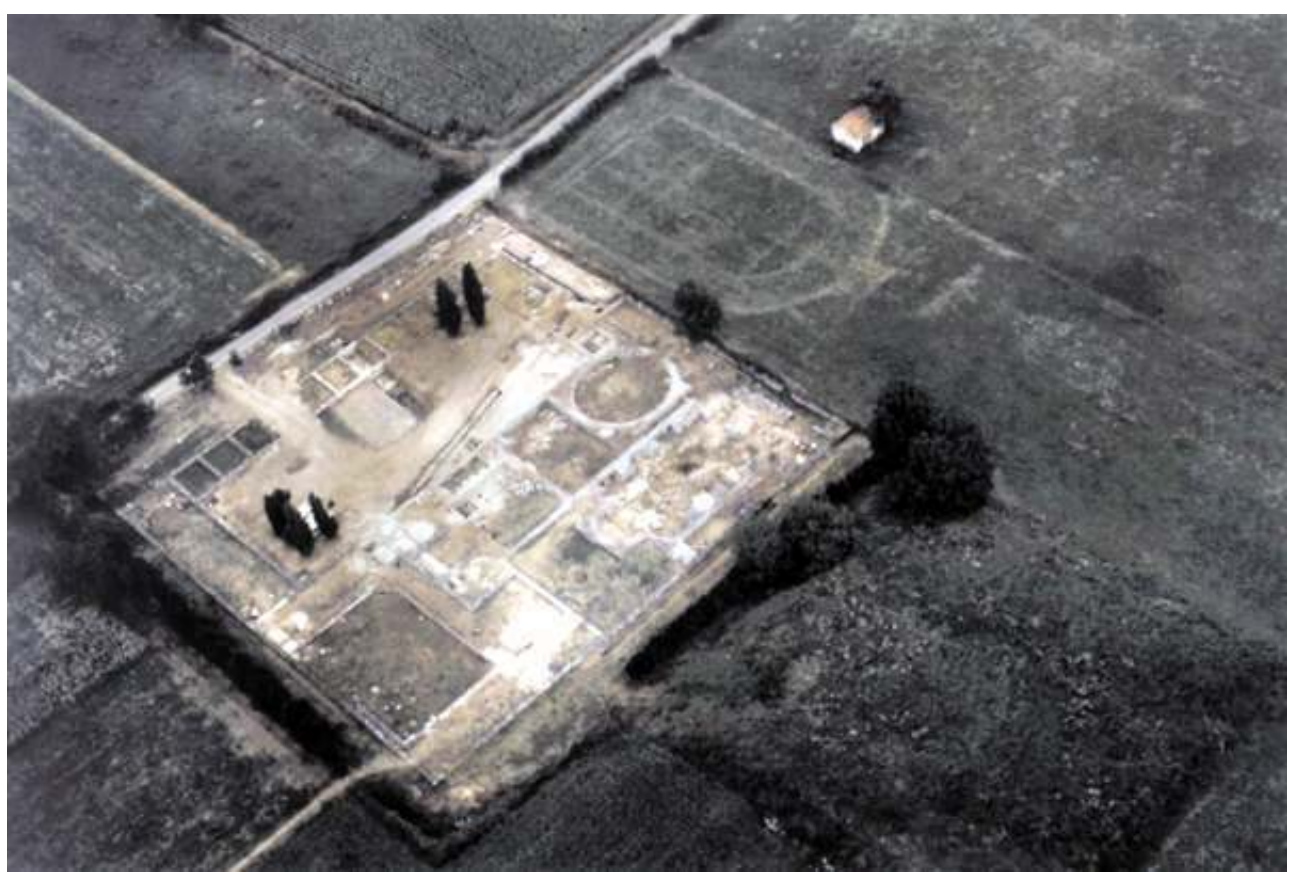

Auteur(s) : Petit, Catherine. Crédits : Gi 1997 ; CNRS Éditions 1998 (1991) 
INDEX

Index chronologique : Antiquité romaine

Index géographique : Midi-Pyrénées, Haute-Garonne (31), Valcabrère, Saint-Bertrand-de-

Comminges

operation Prospection aérienne (PA) 